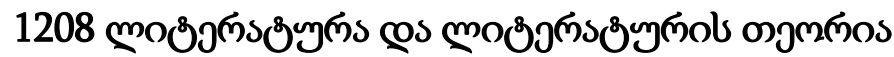

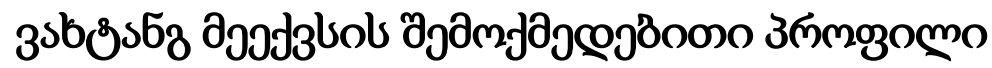

\author{
зомпзда бобм \\ os 3 ma z

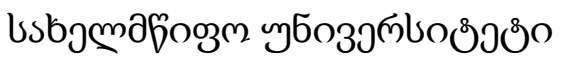

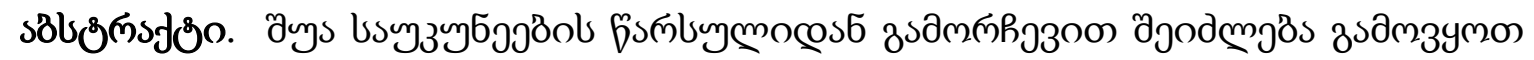

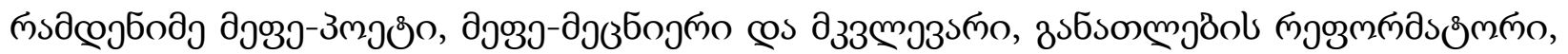

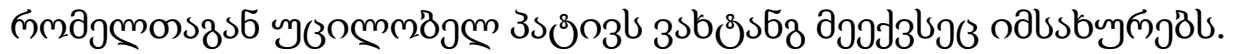

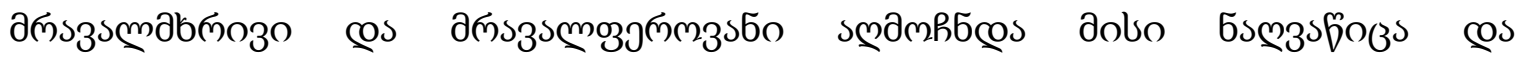

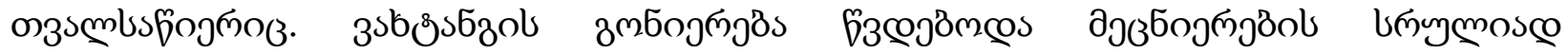

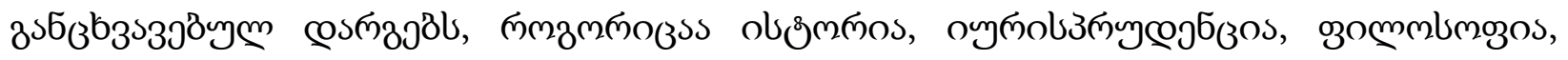

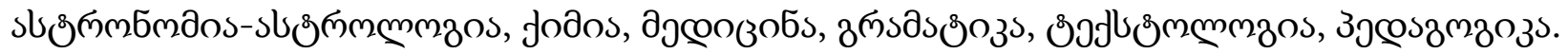

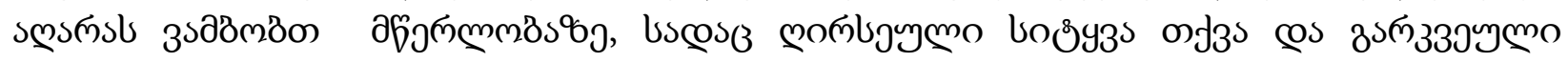

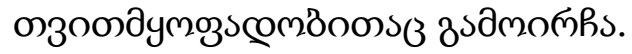

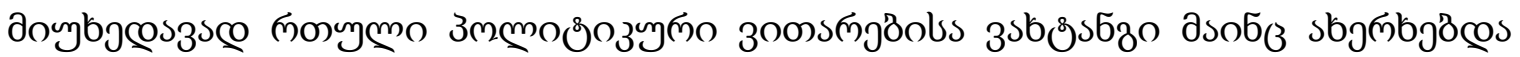

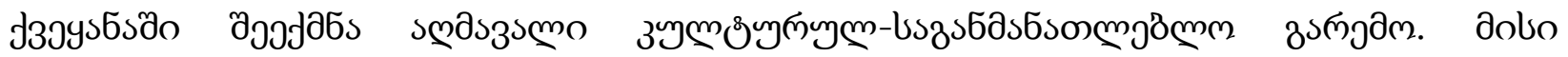

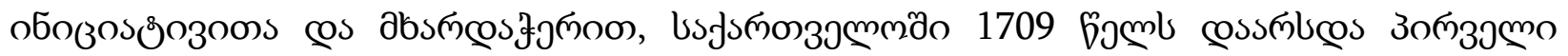

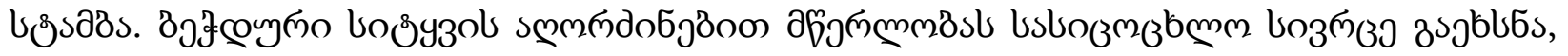

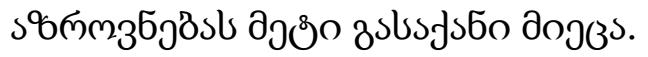

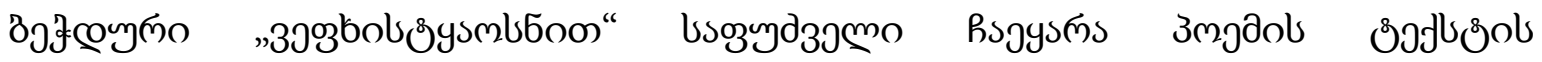

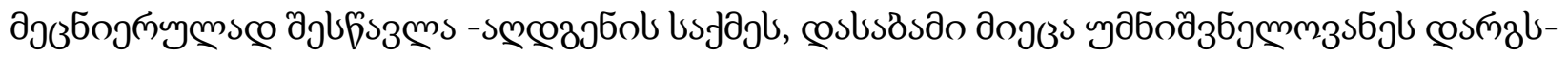

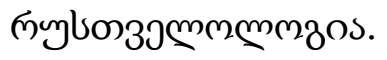

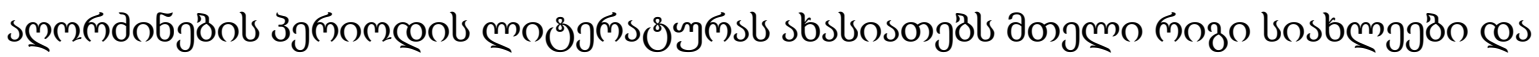

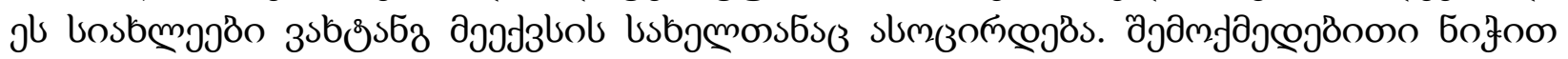

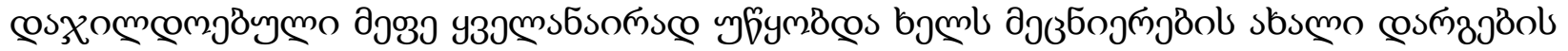

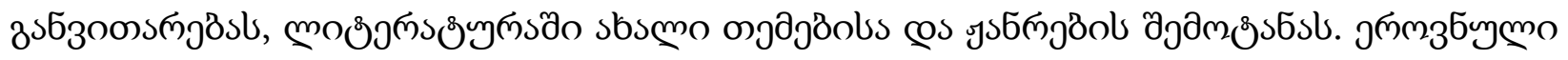

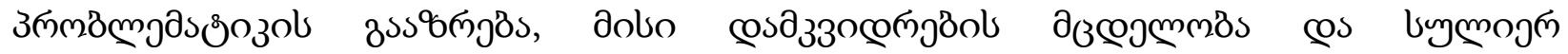

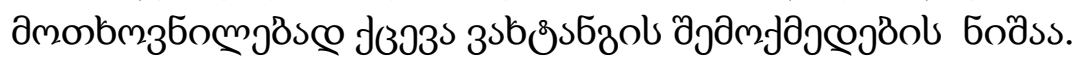

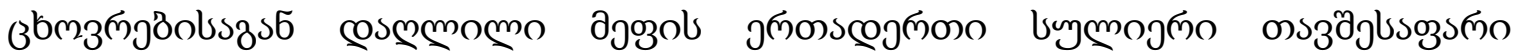

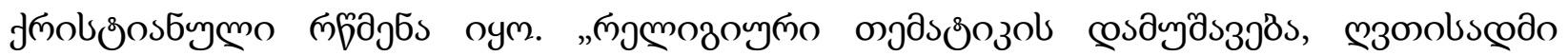

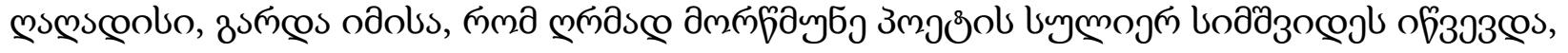




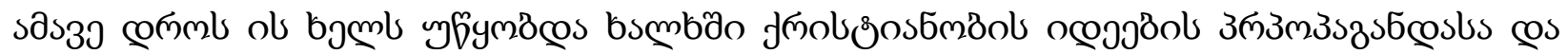

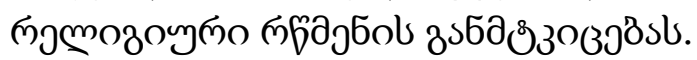

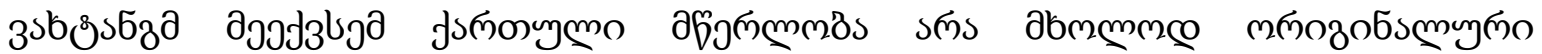

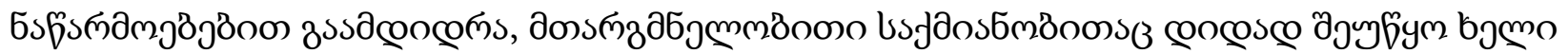

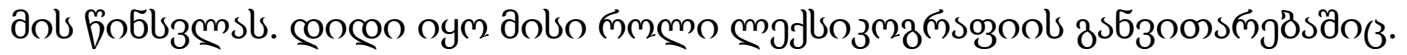

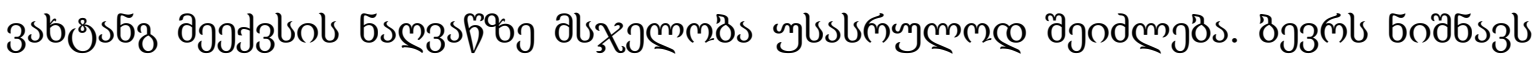

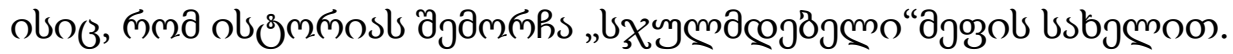

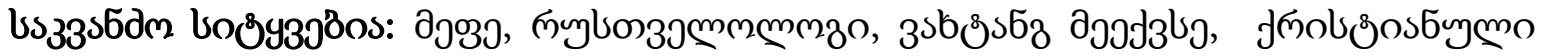

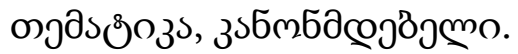

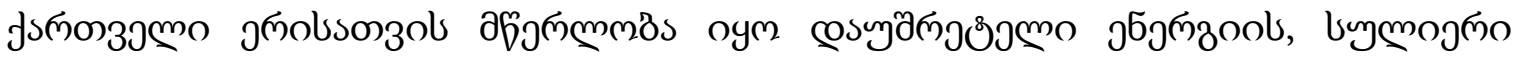

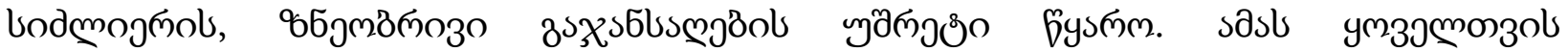

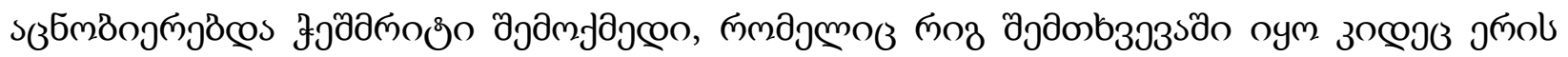

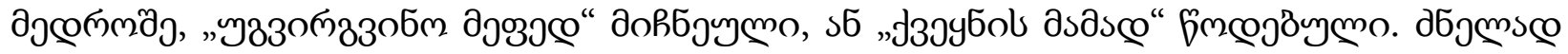

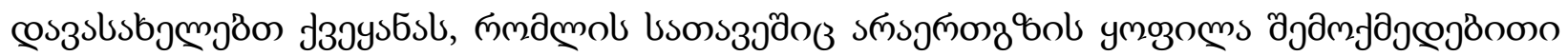

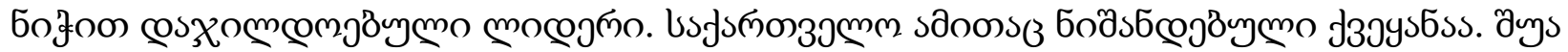

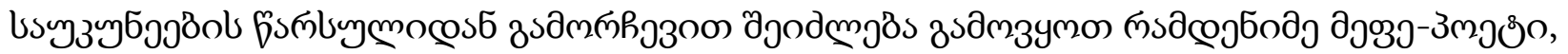

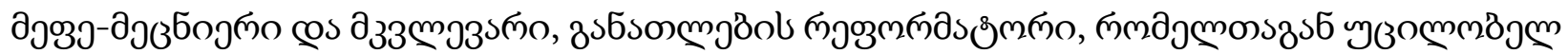

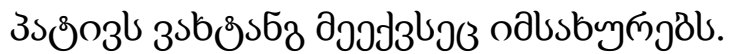

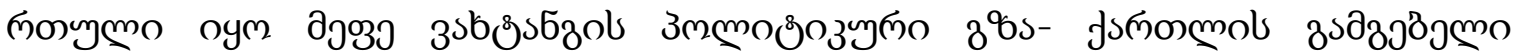

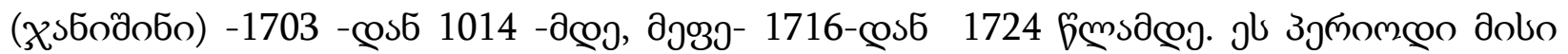

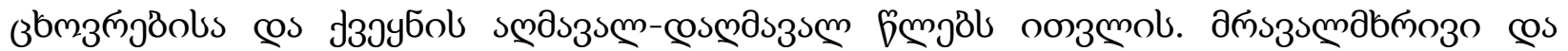

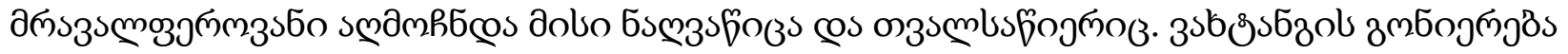

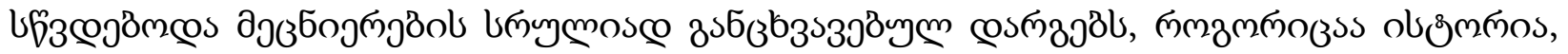

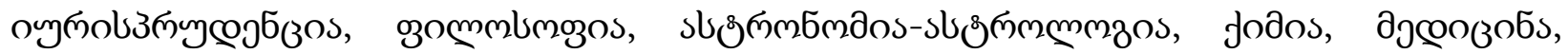

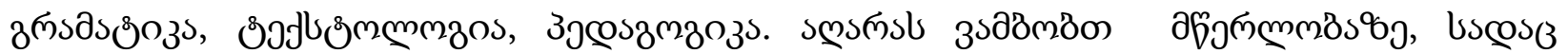

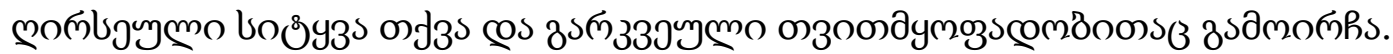

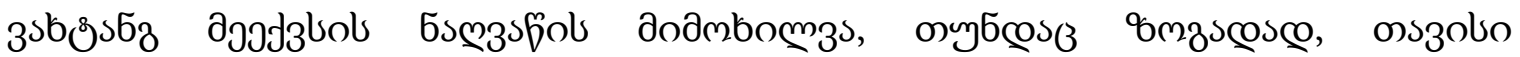

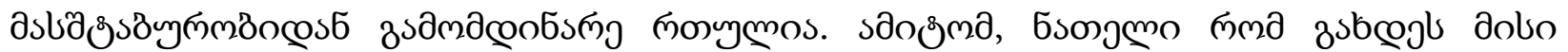

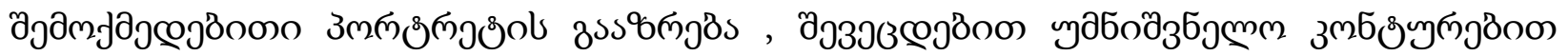

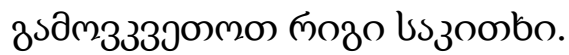

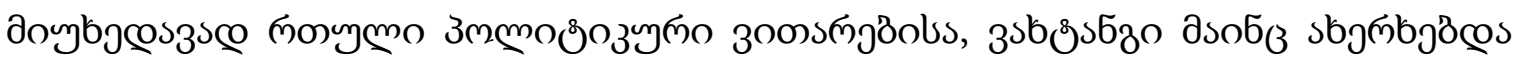

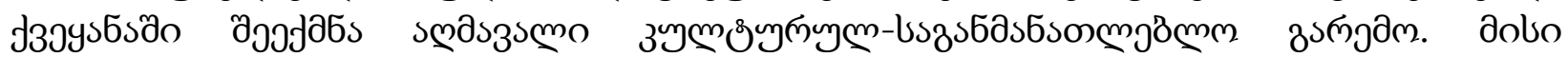

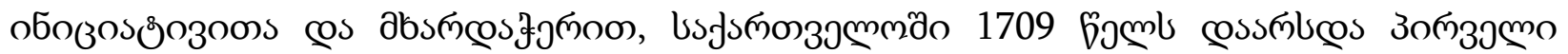

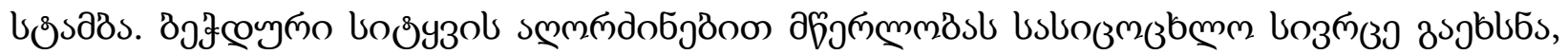

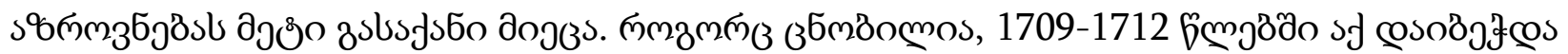

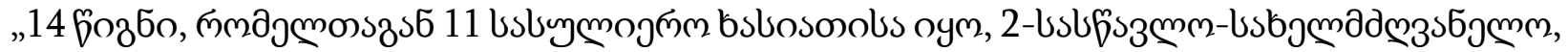

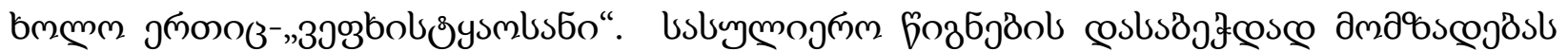

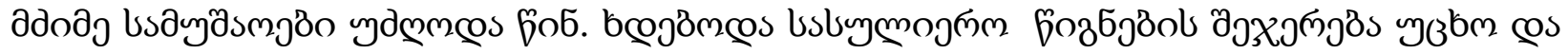




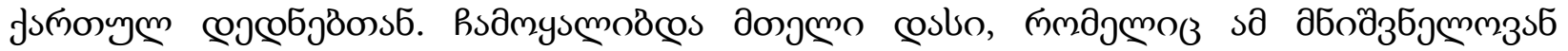

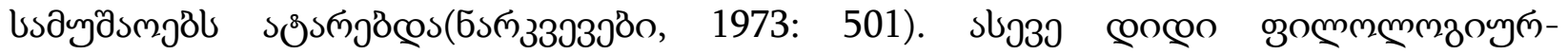

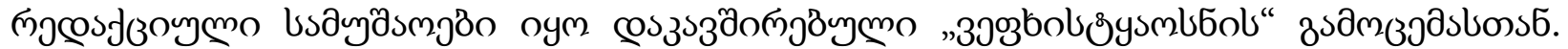

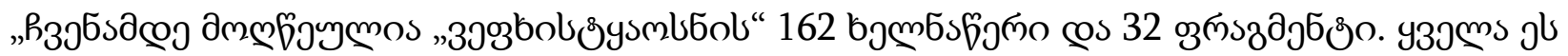

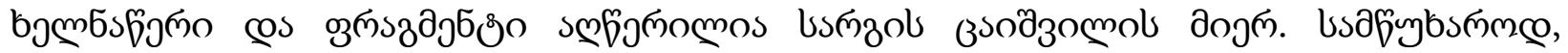

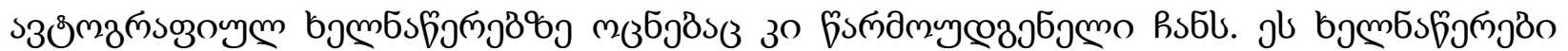

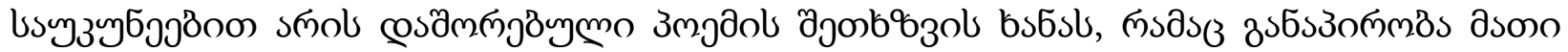

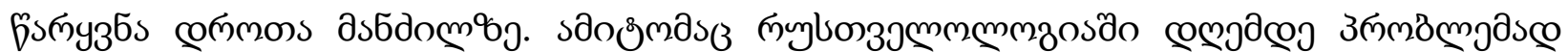

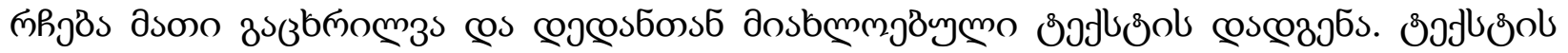

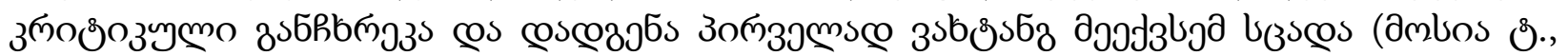
2016:5).

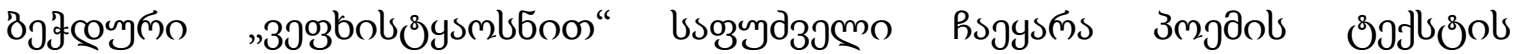

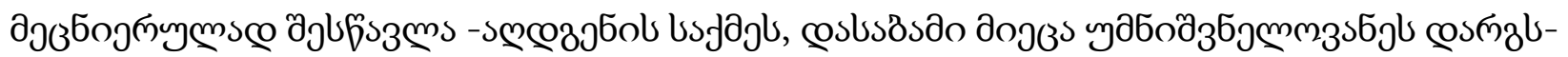

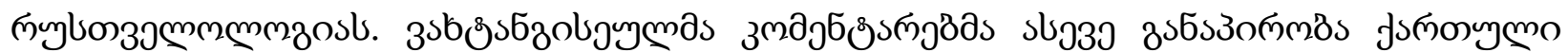

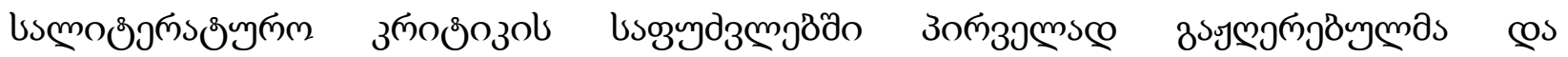

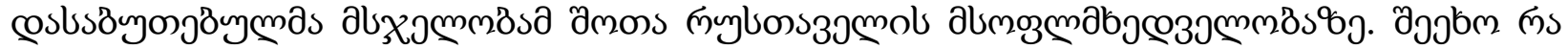

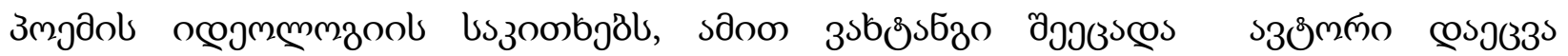

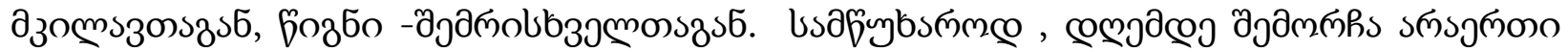

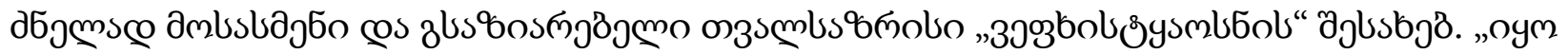

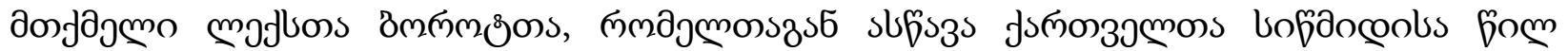

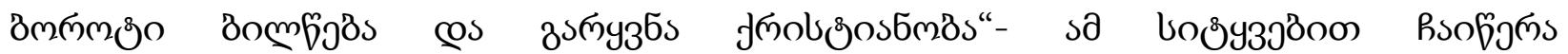

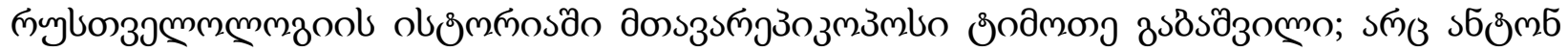

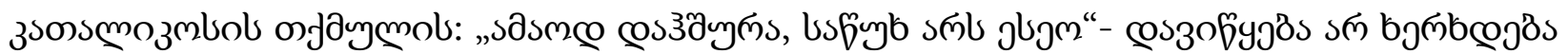

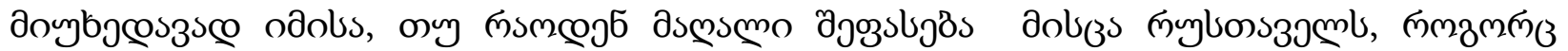

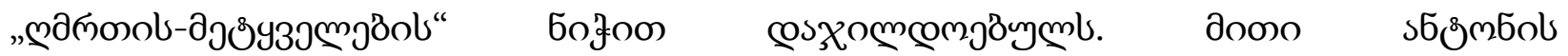

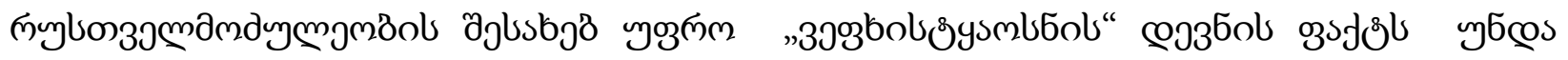

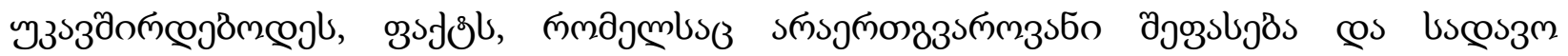

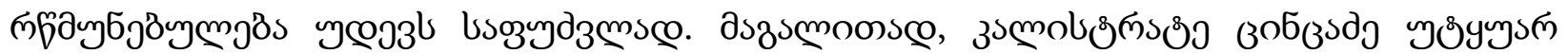

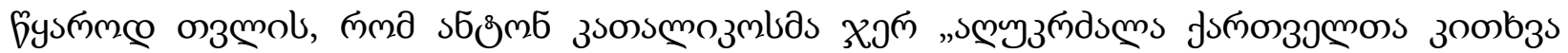

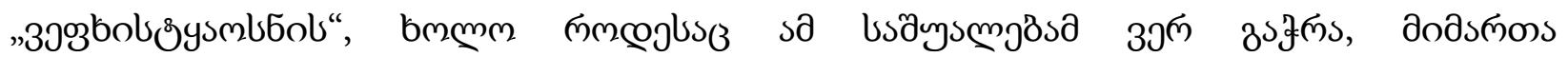

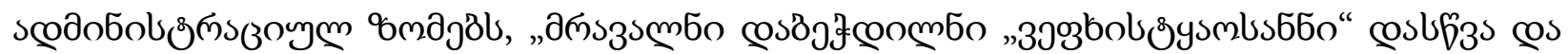

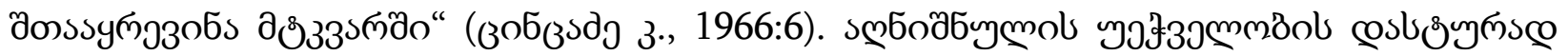

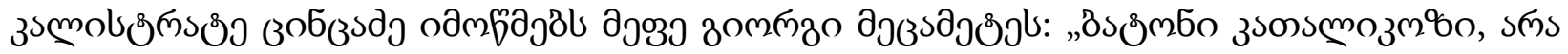

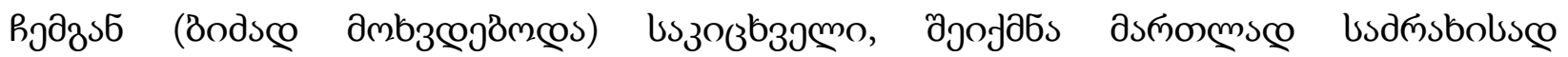

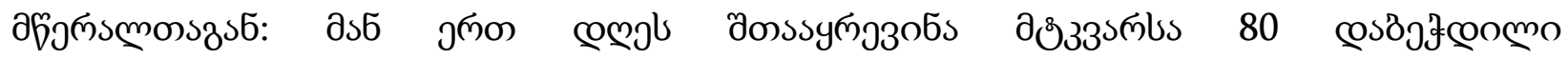

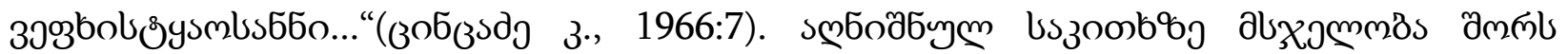

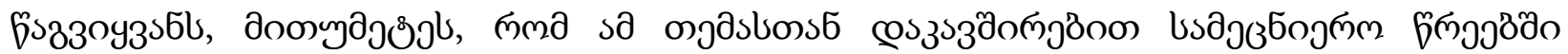

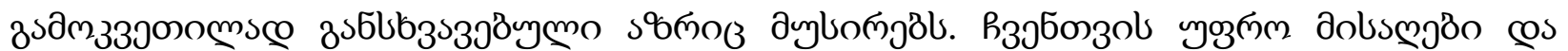

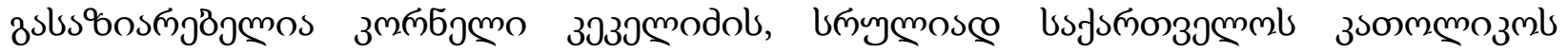

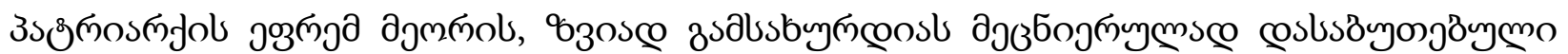

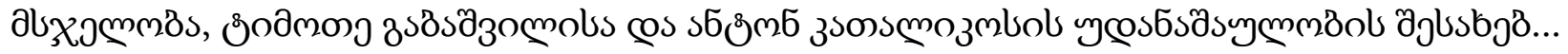




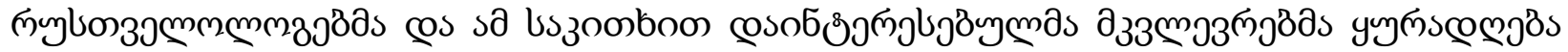

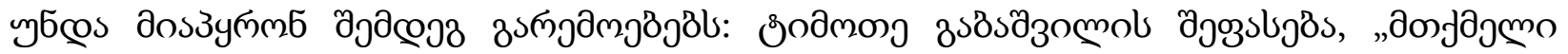

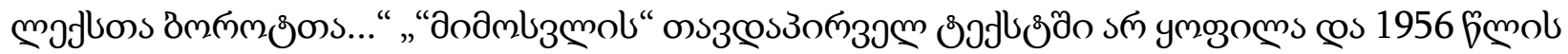

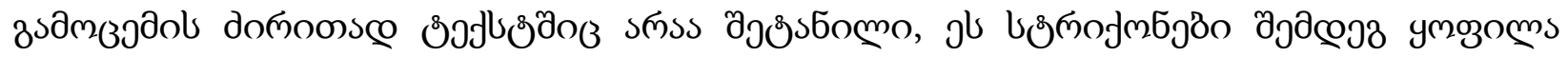

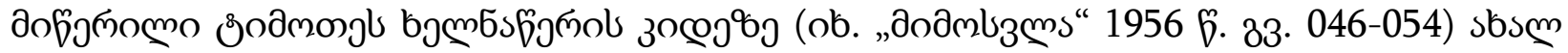

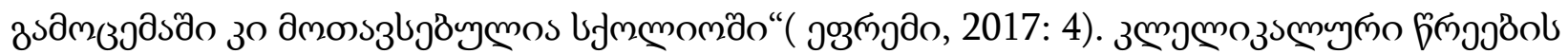

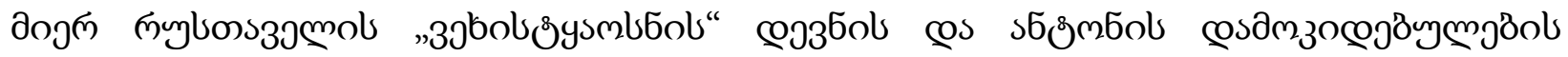

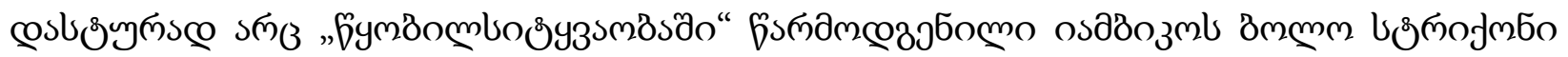

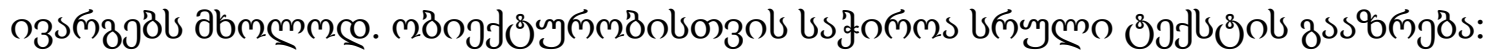

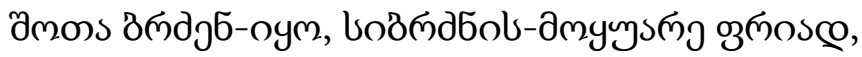

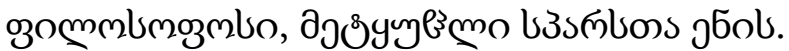

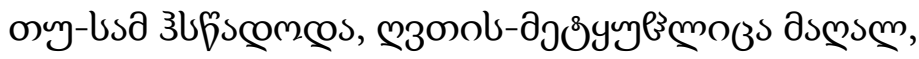

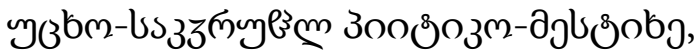

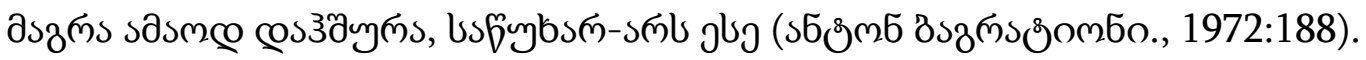

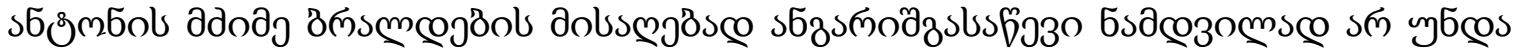

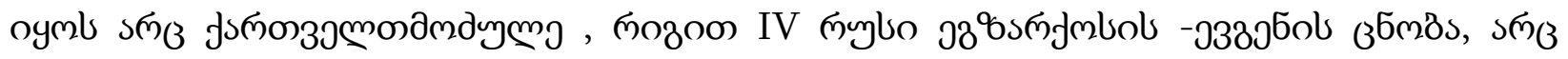

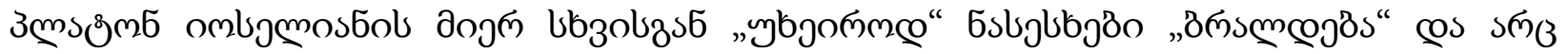

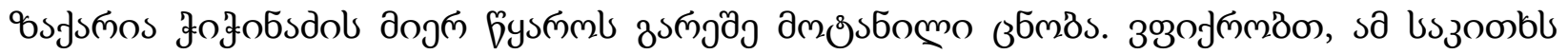

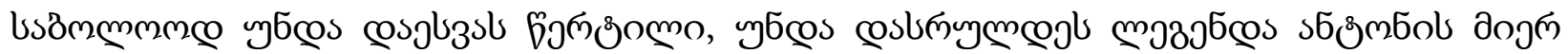

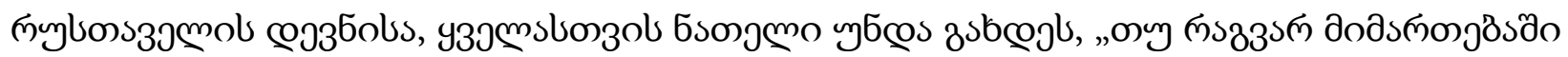

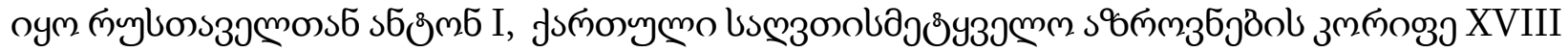

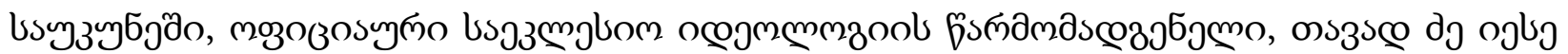

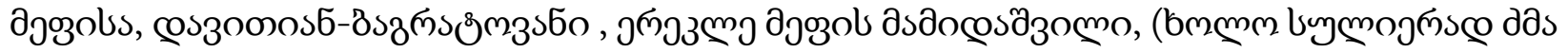
djơols) „, (zsalsbuym coos \%., 1991:49).

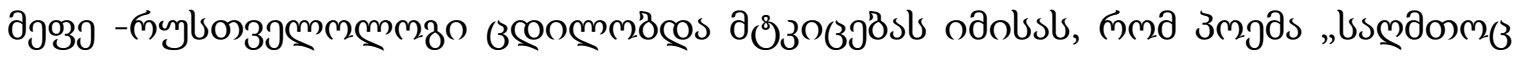

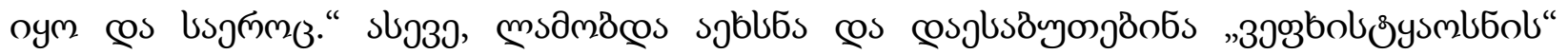

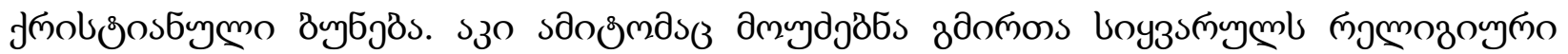

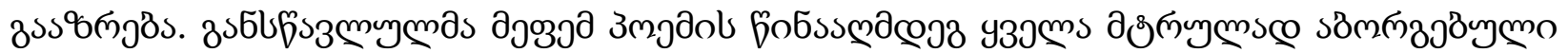

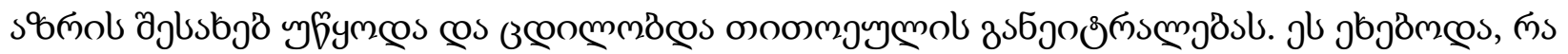

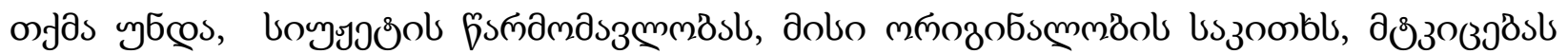

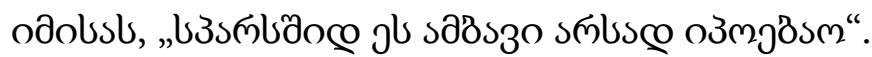

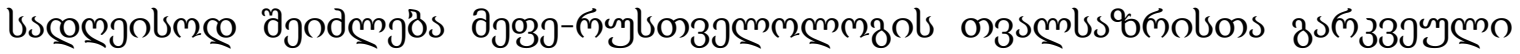

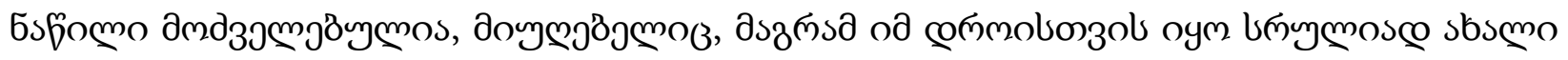

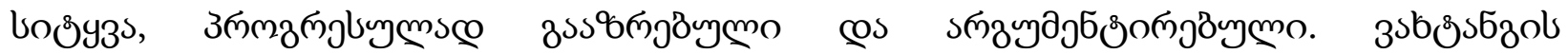

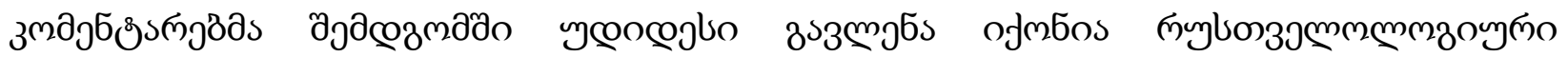

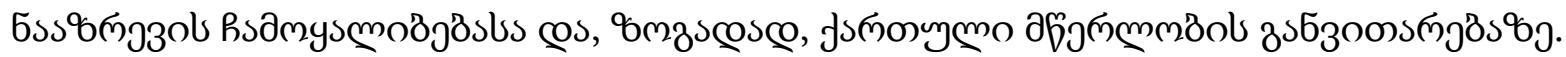

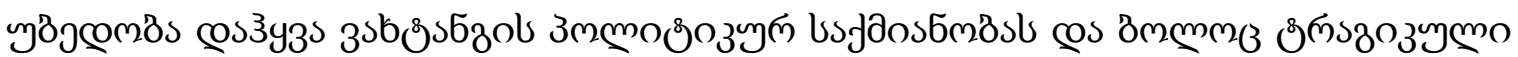

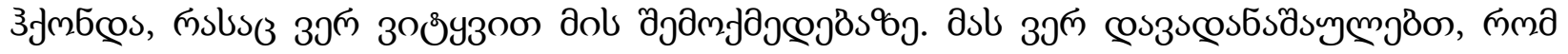

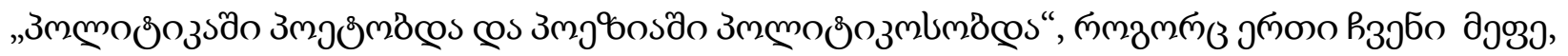

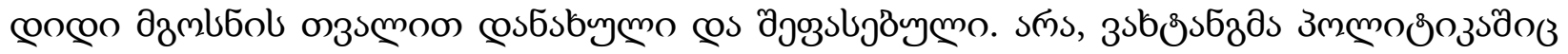




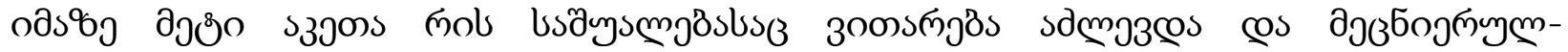

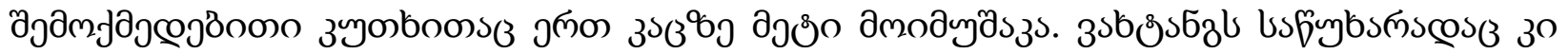

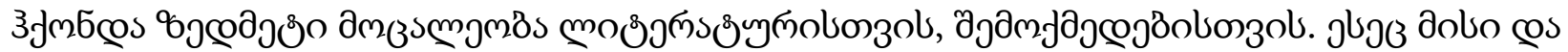
dobo j3yyбol sి

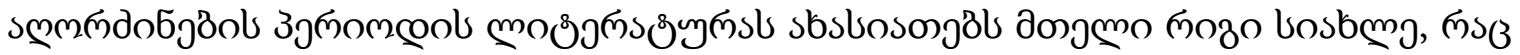
3

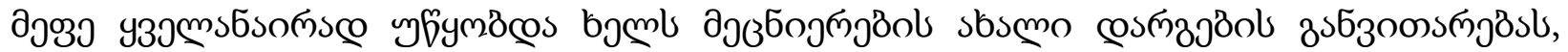

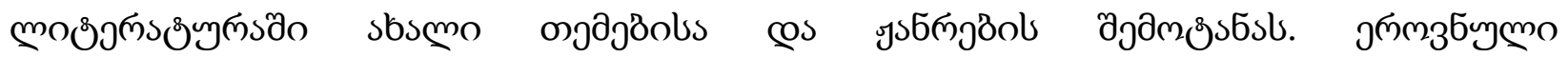

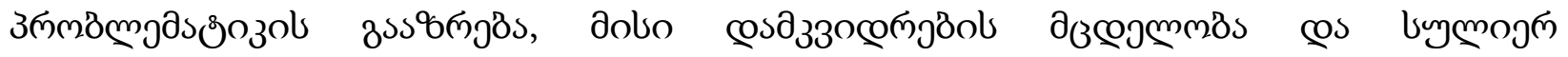

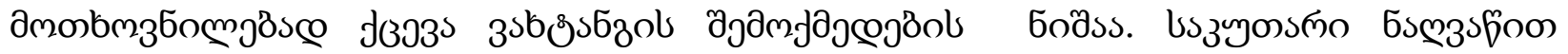

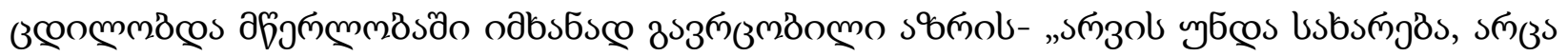

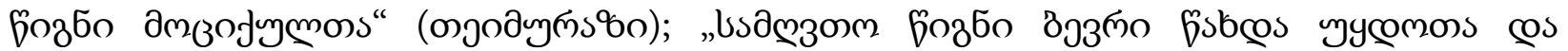

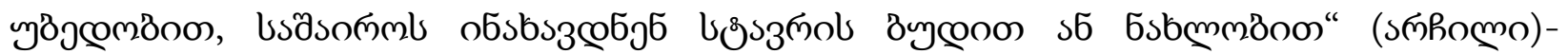

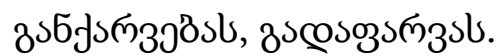

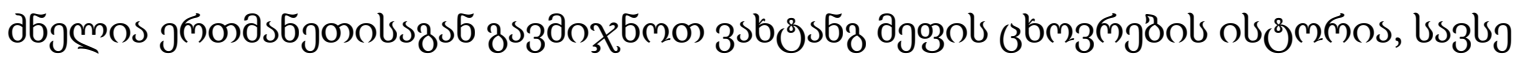

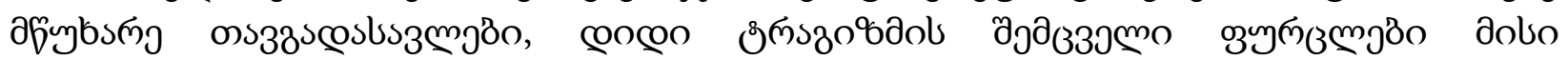

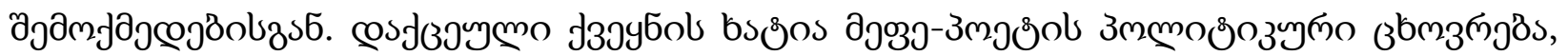

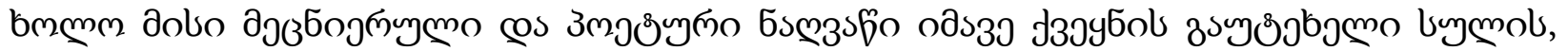

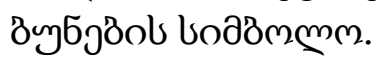

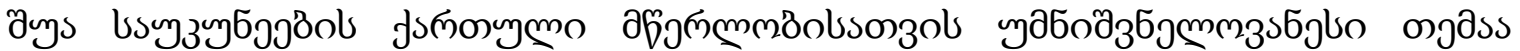

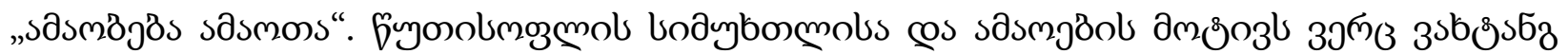

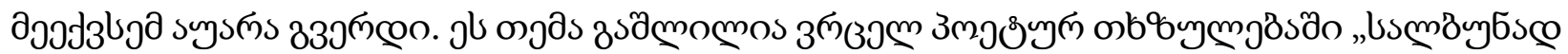

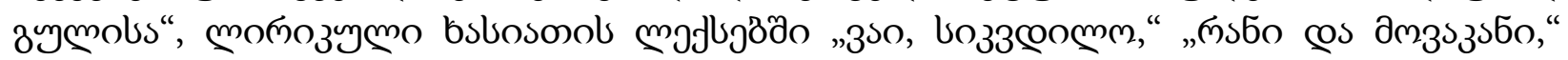

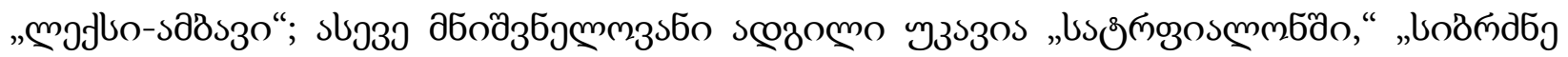

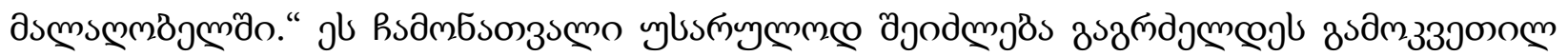

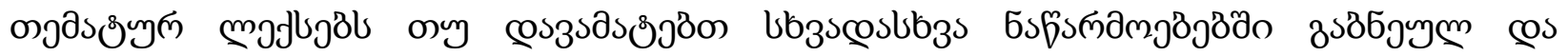

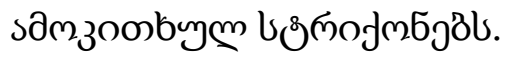

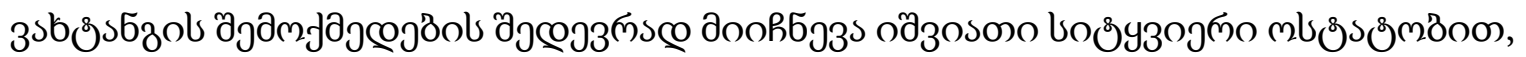

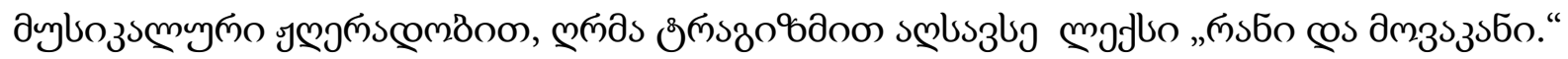

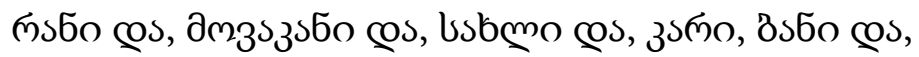

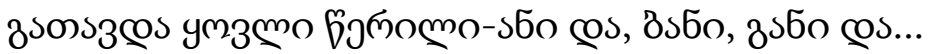

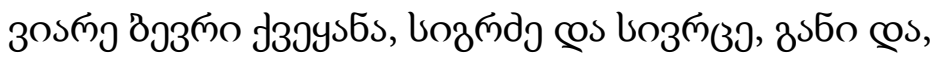

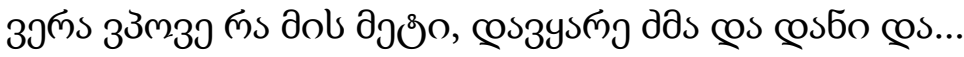

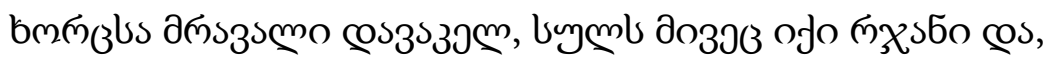

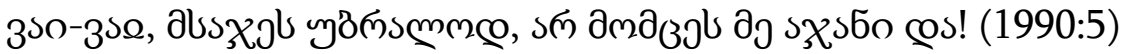

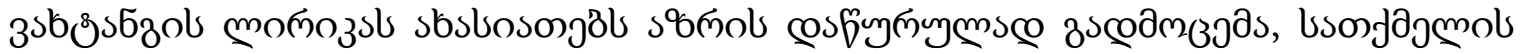

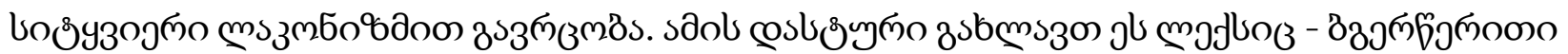

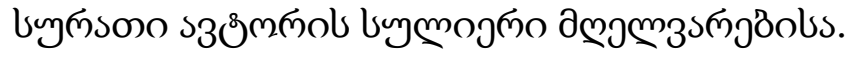

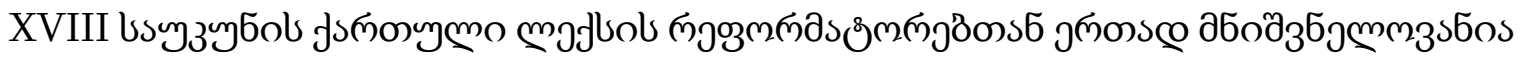

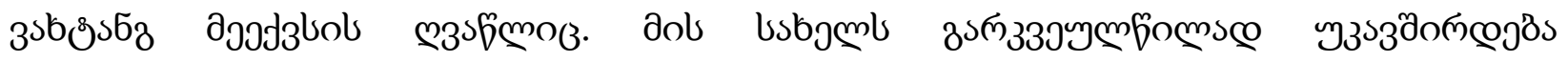




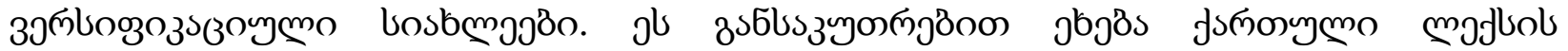

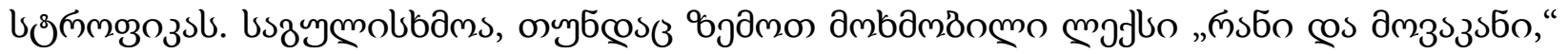

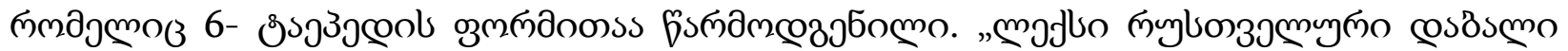

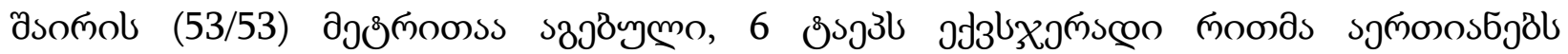

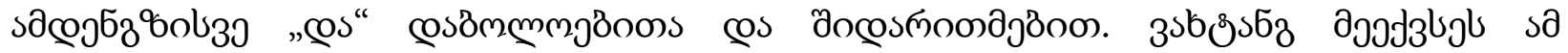

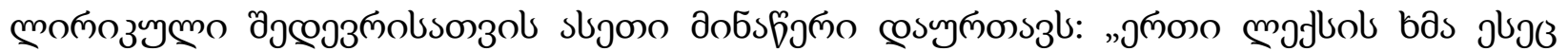

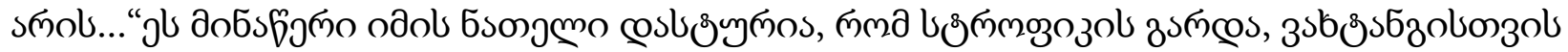

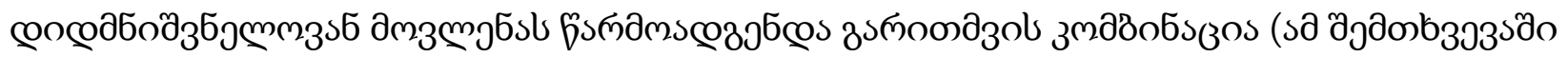

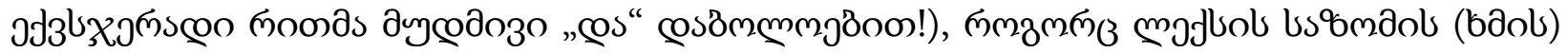

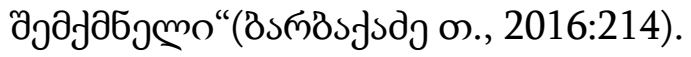

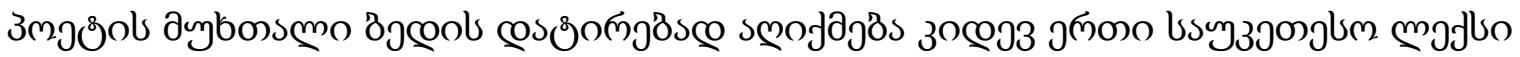

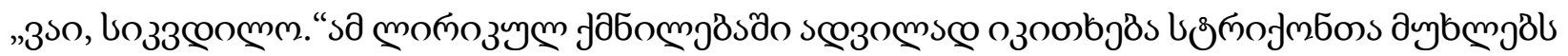

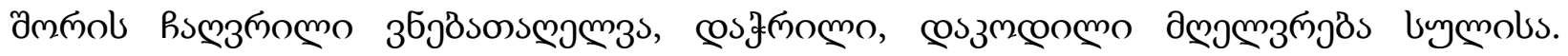

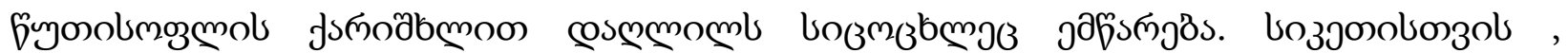

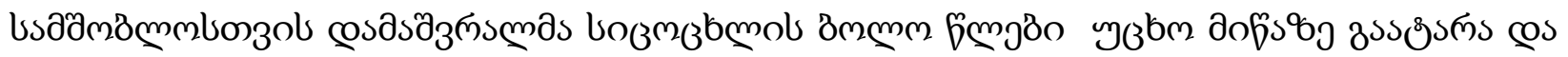

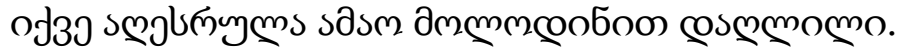

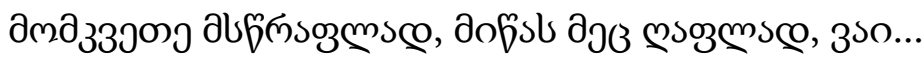

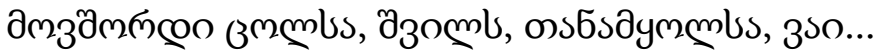

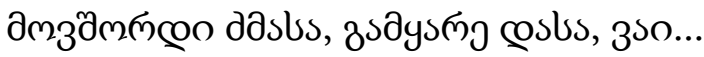

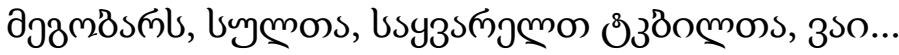

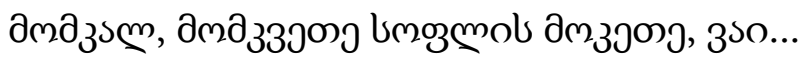

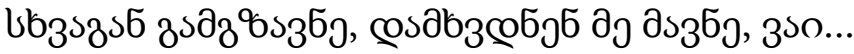

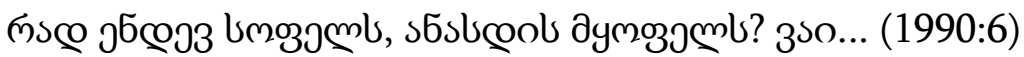

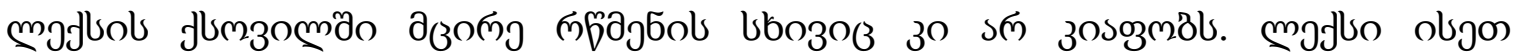

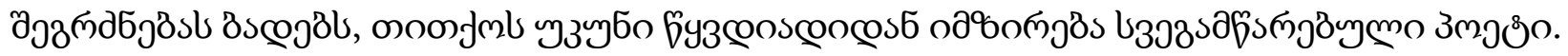

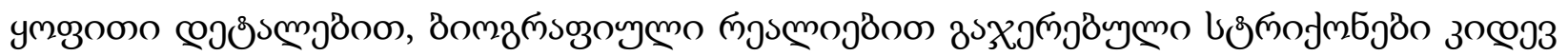

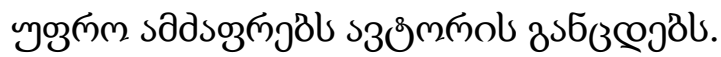

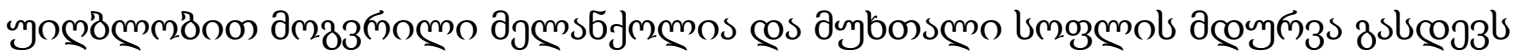

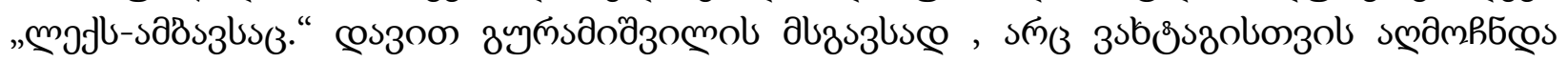

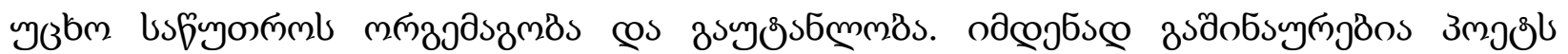

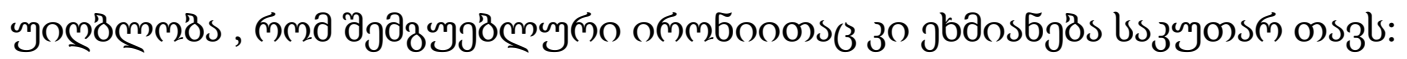

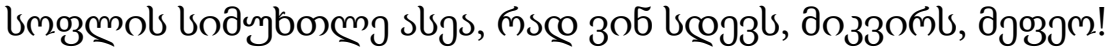

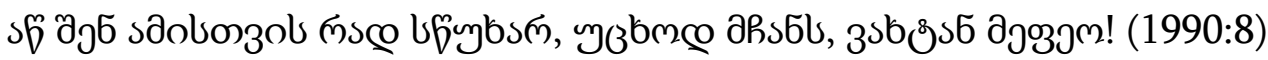

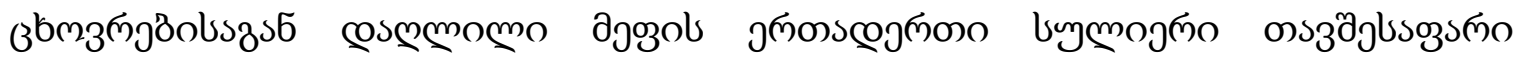

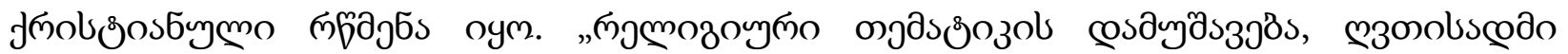

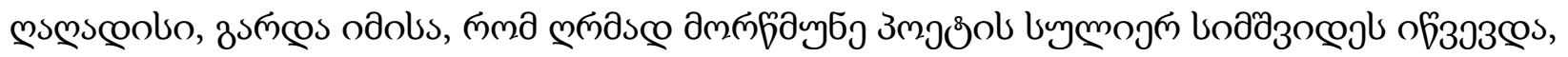

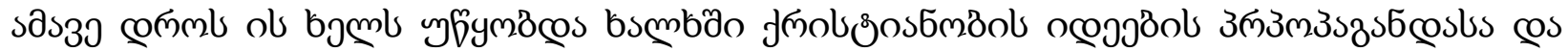

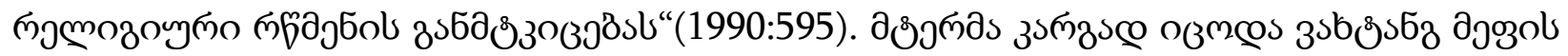

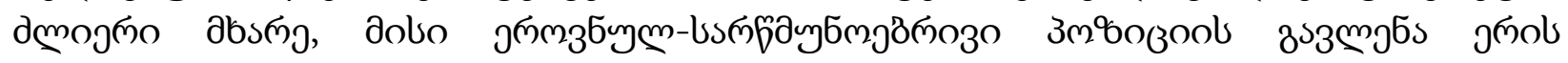




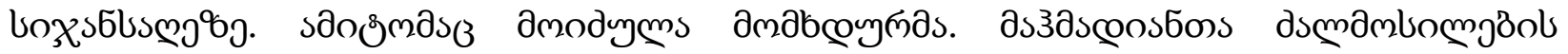

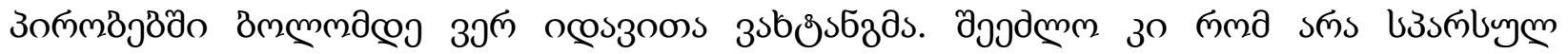

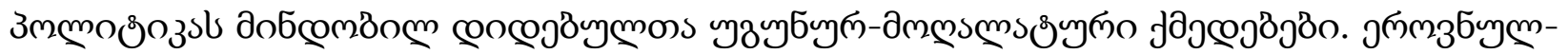

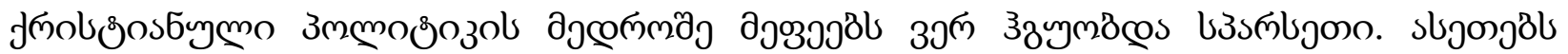

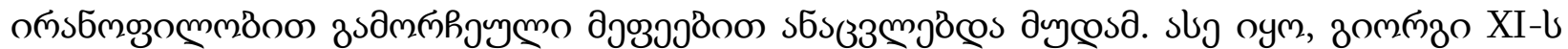

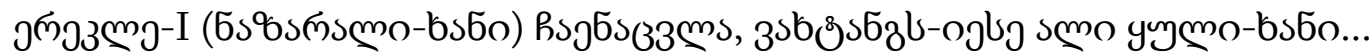

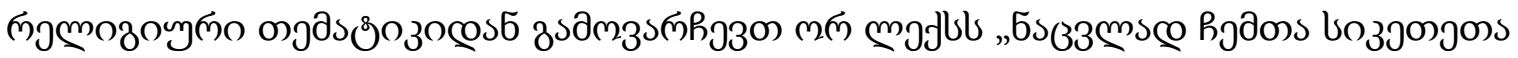

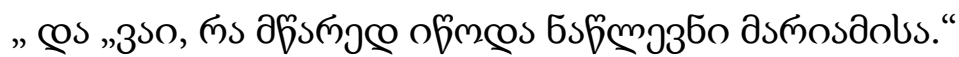

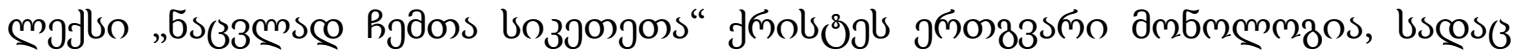

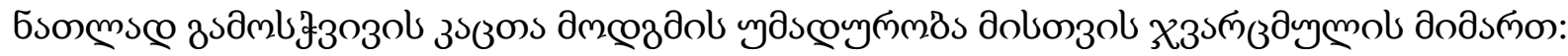

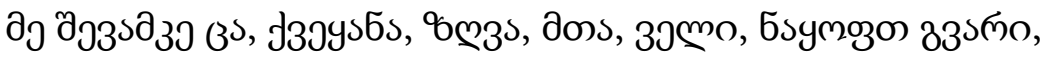

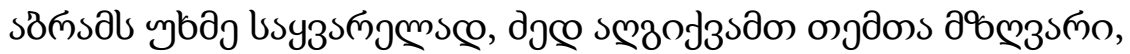

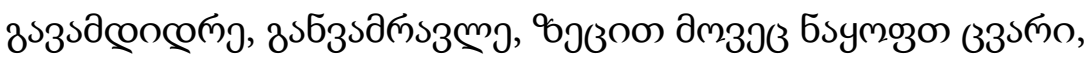

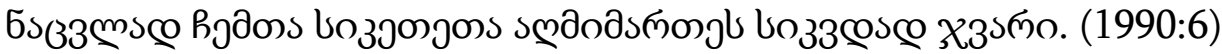

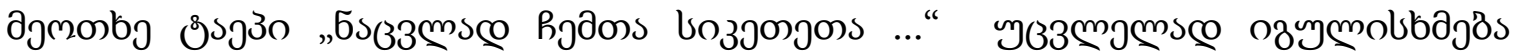

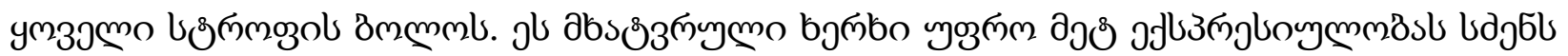

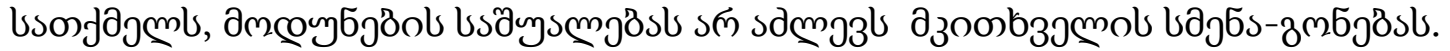

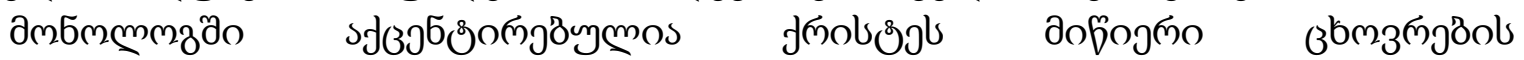
эдбодзб

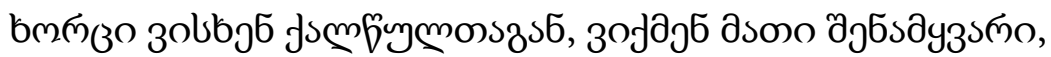

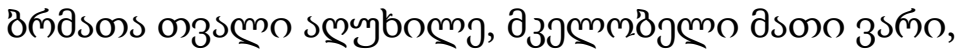

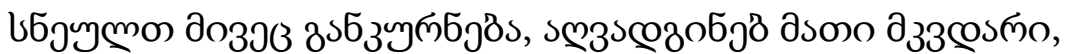

бьззмзм...(1990:6)

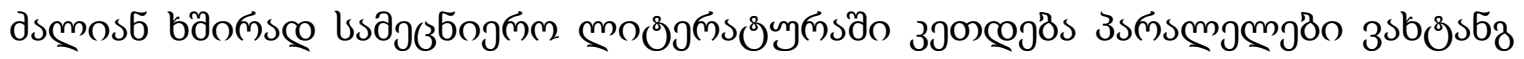
дjoj3

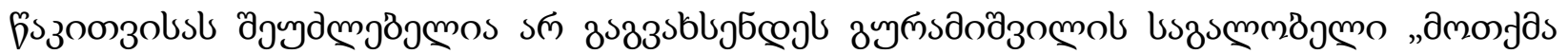

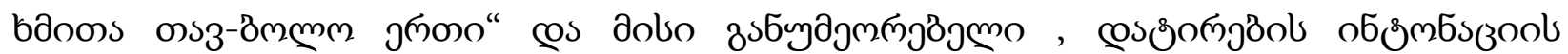

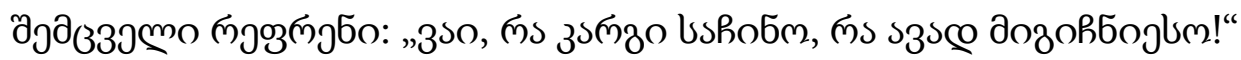

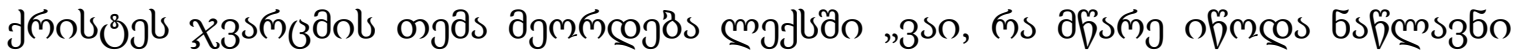

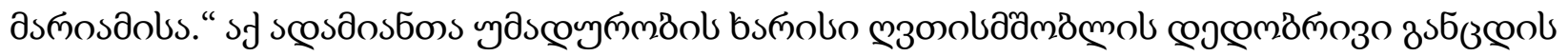

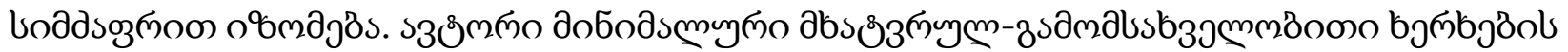

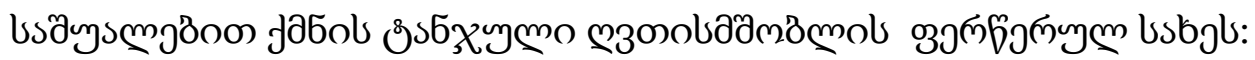

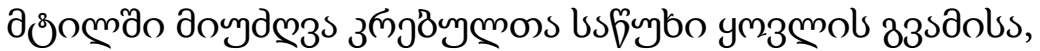

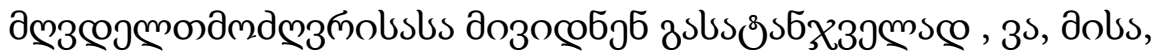

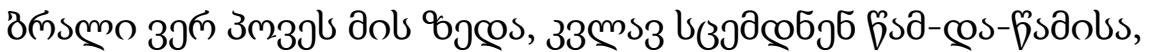

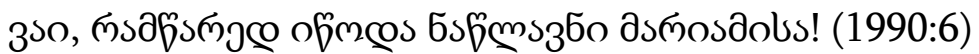

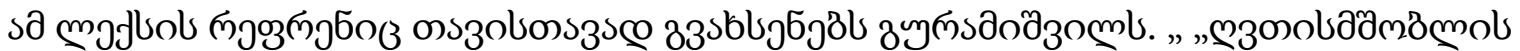

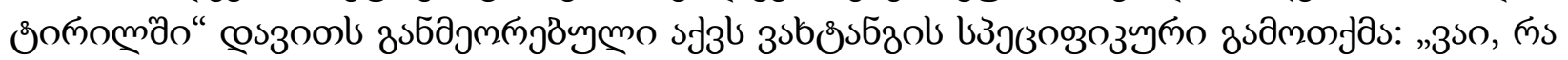

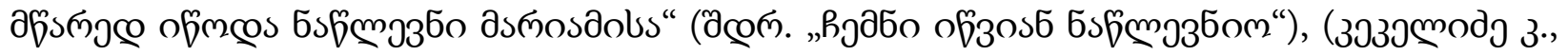




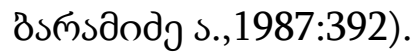

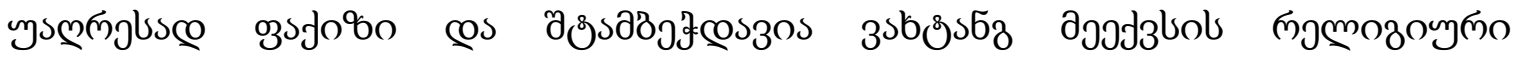

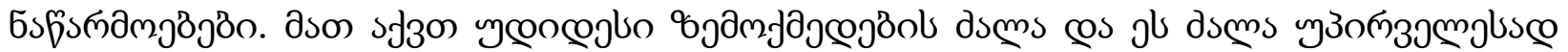

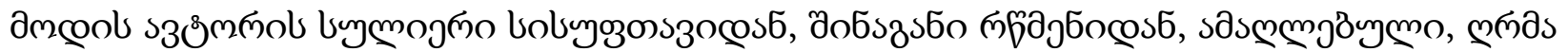

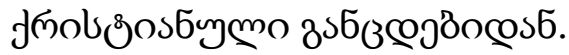

З

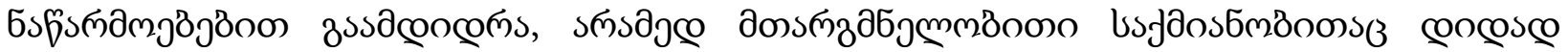

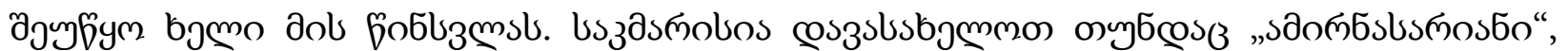

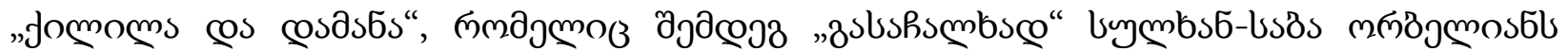
доsбçm.

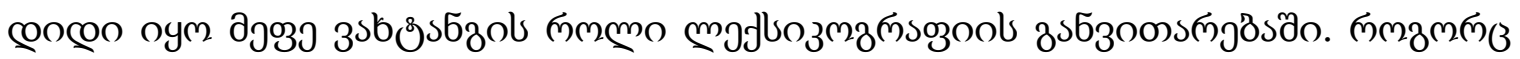

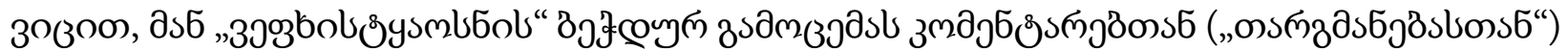

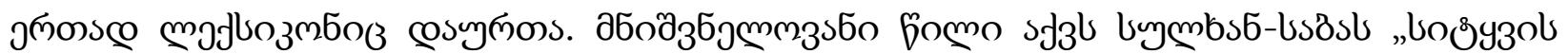

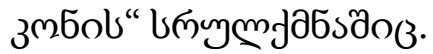

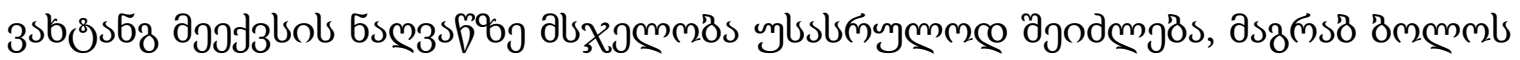

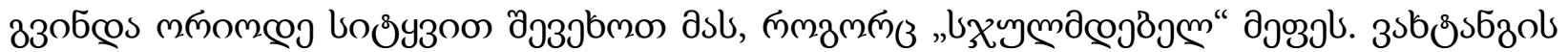

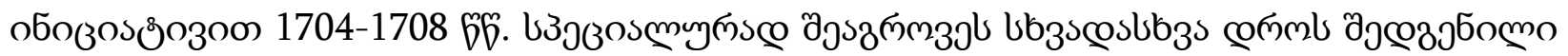

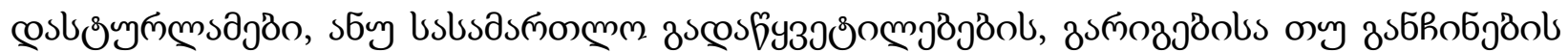

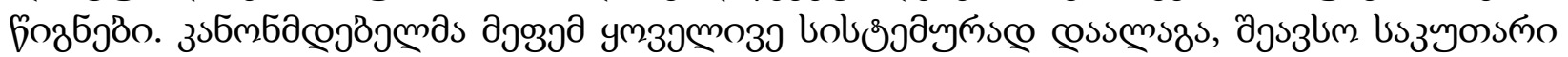

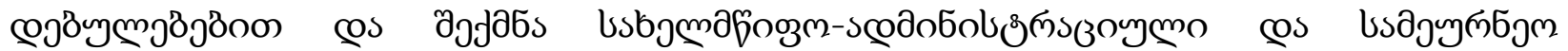

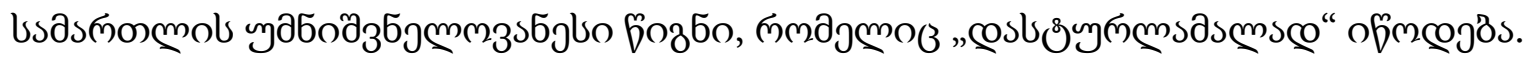

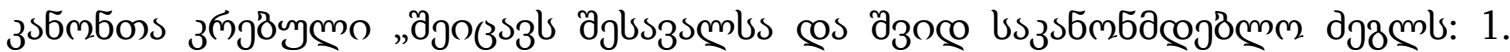

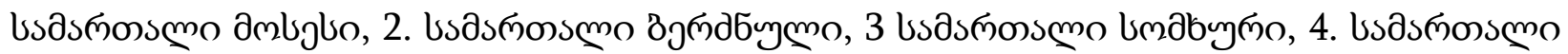

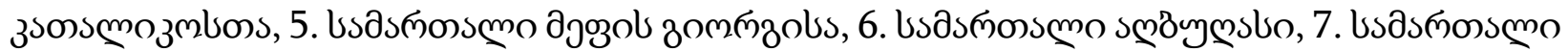

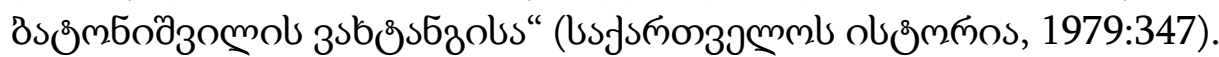

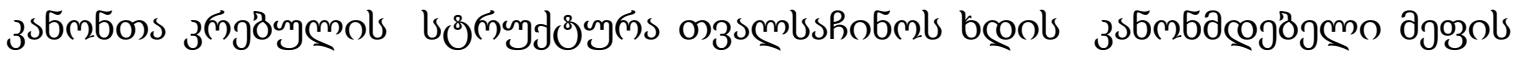

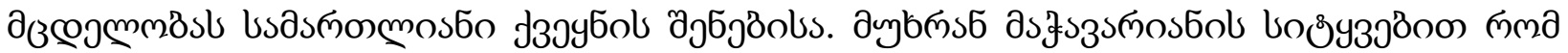

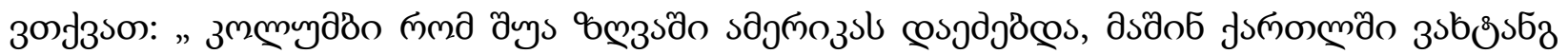

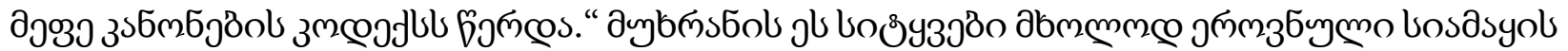

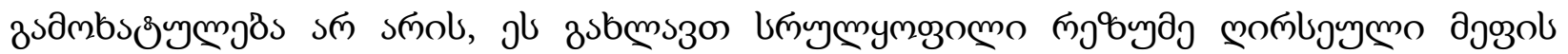
Бsm3sfous.

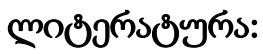

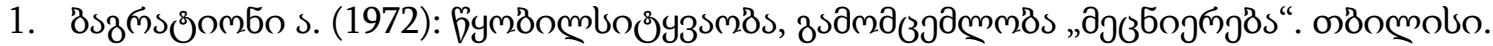

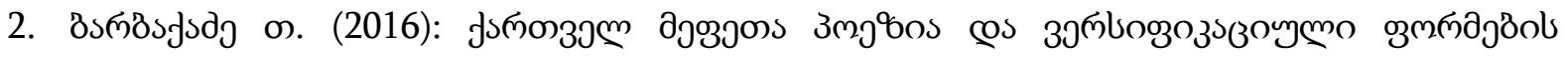

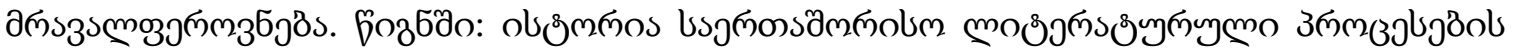

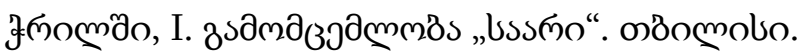

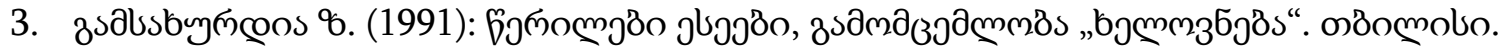




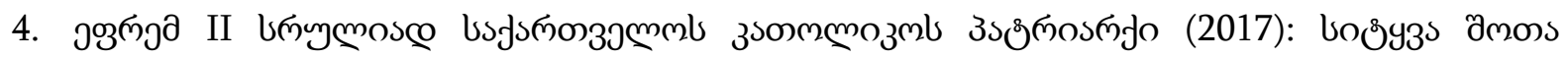

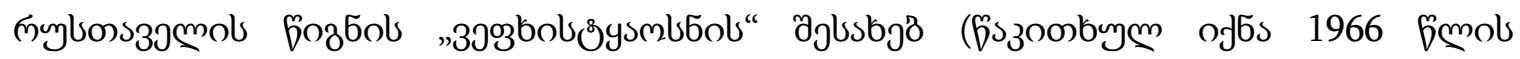

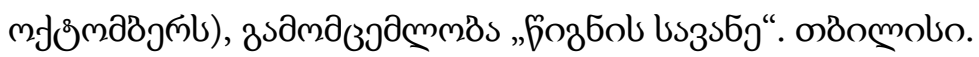

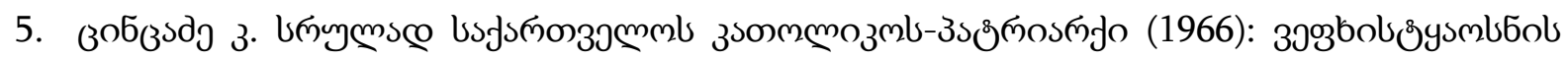

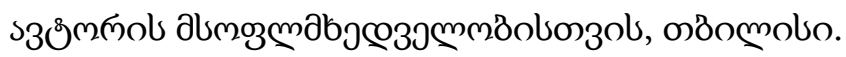

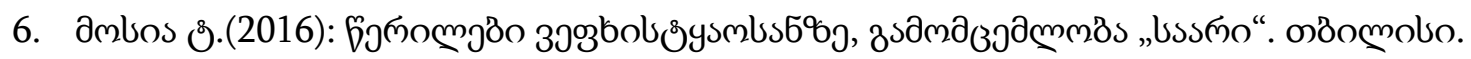

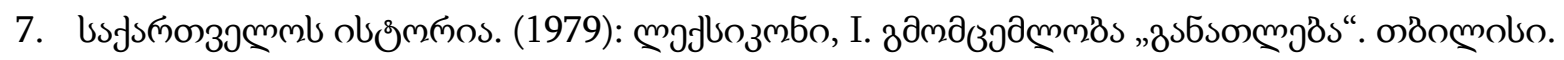

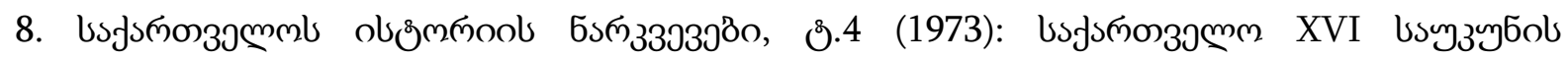

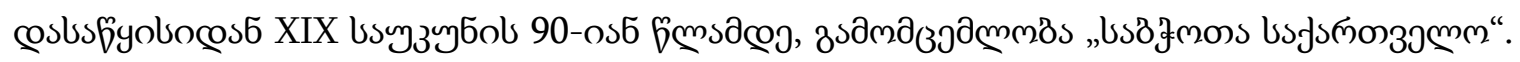
obomolo.

\title{
Fictive Protrait of the King Vakhtang VI
}

Giorgadze Nino

Iakob Gogebashvili Telavi State University

\begin{abstract}
From the medieval past we can single out several kings-poets, kings-scientists and scholars, education reformers, of whom Vakhtang VI deserves great respect.

Versatile and varied turned out to be his genius and spectacle as well. King Vakhtang's intellect was accessible to completely different fields of science, such as history, jurisprudence, philosophy, astronomy-astrology, chemistry, medicine, grammar, textology, pedagogy. Not to mention the writing, where he said a decent word.

Despite the difficult political situation, King Vakhtang VI still managed to create a prosperous cultural and educational environment in the country. With his initiative and support, the first printing house was established in Georgia in 1709. With the revival of the printed word, writing opened up vital space, giving more thought to thinking.

By printing "The Knight in the Panther's Skin" the foundation was laid for the scientific study of the text of the poem - the work of restoration, the foundation was given to the most important field - Rustvelology.

The literature of the Renaissance period is characterized by a number of novelties associated to the name of the King Vakhtang VI. The King, endowed with creative talent, contributed in every way to the development of new fields of science, the introduction of new themes and genres in literature. Understanding the national problem, trying to establish it and turning it into a spiritual need is the niche of Vakhtang's creativity.

The only spiritual refuge of the king tired of life was the Christian faith. "The elaboration of religious themes, the cry to God, in addition to bringing spiritual peace to the deeply believing poet, at the same time he promoted the ideas of Christianity among the people and
\end{abstract}


strengthened the religious faith.

King Vakhtang VI not only enriched the Georgian literature with his original works, but also greatly contributed to his translation activities. His role in the development of lexicography was also great.

The genius of Vakhtang VI can be discussed endlessly. It means a lot even to the fact that the history has survived in the name of the "lawgiver" king.

Keywords: King, Rustvelologist, Vakhtang VI, Christian theme, legislator. 